\title{
O uso do Instagram pela Assembleia Legislativa de Mato Grosso como ferramenta de Comunicação Pública
}

\author{
Bernadete da Silva Santos $^{1}$, Maria Felícia Santos da Silva ${ }^{1}$, Cristiano Maciel $^{1}$ \\ ${ }^{1}$ Universidade Federal de Mato Grosso - Cuiabá - MT - Brasil \\ \{bssantos.adm, crismac\}@gmail.com, felicias@uol.com.br
}

\begin{abstract}
The increasing use and reach of social networks nowadays led public organizations to seek new ways to use them to transmit information to citizens. This research analyzes the types of information in public communication by the Legislative Assembly of Mato Grosso its profile on Instagram from 2018 to 2020. The data shows an institutional interest in transmitting information about political decisions, available services, campaigns, rights enforced by law, as well as other kinds of information related to citizens' daily lives.

Resumo. O crescimento na utilização das redes sociais, bem como seu alcance na sociedade atual, tem levado as organizações públicas a buscarem formas de utilizá-las para transmissão de informação para o cidadão. Nesta esteira, esta pesquisa analisa os tipos de informação mais utilizadas no âmbito da Comunicação Pública pela Assembleia Legislativa de Mato Grosso, em seu perfil no Instagram entre os anos de 2018 e 2020. Os dados demonstram interesse institucional em transmitir informações sobre suas decisões politicas, bem como divulgar serviços disponíveis, campanhas, direitos protegidos por lei e outras informações ligadas ao cotidiano do cidadão.
\end{abstract}

\section{Introdução}

Diversos órgãos governamentais já estão presentes nas principais redes sociais e, apesar de existirem indicações e recomendações do Poder Executivo Federal para uso destas ferramentas, cada órgão é responsável pela própria estratégia de identidade nestas mídias. Alguns órgãos, como a Prefeitura de Curitiba, por exemplo, utilizam seus perfis de forma bem-humorada e adequando suas postagens à linguagem normalmente utilizada em redes sociais, buscando dessa forma provocar a aproximação entre os órgãos públicos e sua população (Santos e Harmata, 2013). Outros utilizam as plataformas de maneira mais formal, como o Senado Federal, que está presente em várias mídias sociais e transmite informações institucionais utilizando uma linguagem de fácil acesso a qualquer usuário. Esse movimento torna importante a busca por maneiras de utilização desses meios comunicacionais de forma positiva e a favor tanto do ente público quanto do cidadão.

A pesquisa Social Media Trends (Rock Content, 2019) aponta que 96,2\% dos usuários de Internet no Brasil fazem uso de redes sociais. Entre os entrevistados 92,1\% utilizam o Facebook e 92,5\% utilizam o Instagram (este último apresentando aumento na utilização em comparação ao ano anterior, enquanto o Facebook apresentou leve queda). Segundo a pesquisa 91,3\% dos internautas respondentes afirmam acessar suas redes sociais diariamente, sendo que 38,3\% destes gastam mais de 4 horas diárias nessas redes. Outro dado importante, apresentado pela Pesquisa Nacional por Amostra de Domicílios Contínua, aponta que $74,7 \%$ da população com mais de 10 anos de idade utilizou a Internet no período de referência da pesquisa e que, destas pessoas, $98,1 \%$ utilizam como 
equipamento de acesso à Internet o telefone móvel celular (IBGE, 2020). Este aumento na utilização de Internet via telefones celulares corrobora com o crescimento do Instagram. Essa rede social traz informações rápidas, geralmente visualizadas de forma contínua, o que viabiliza seu acesso através de smartphones.

No âmbito da Comunicação Pública, que é compreendida como "um processo comunicativo das instâncias da sociedade que trabalham com a informação voltada para a cidadania" (Brandão, 2012, p. 5), pode-se considerar a utilização das redes sociais, devido ao seu alcance atual, como forma de transmissão e disseminação de informações que levem conhecimento ao cidadão e, ao mesmo tempo, fomentem uma cultura de transparência entre os entes públicos. Reforçando essa ideia, em maio de 2018 aconteceu no Senado Federal, o Seminário "O Legislativo e as Mídias Sociais: Desafios e oportunidades de comunicação". Esse evento mostra que o poder público tem consciência da importância e alcance das mídias sociais e que busca formas positivas de utilizá-las, com informações que fomentem a cultura de transparência e divulguem informações relevantes aos usuários. O evento foi transmitido ao vivo pelo canal "TV Senado" no Youtube, onde os vídeos se encontram disponíveis (TV Senado, 2018).

Os cidadãos são parte vital nos processos de mudanças políticas, sociais e culturais e, para que efetivamente se tornem parte disso, é importante que compreendam o funcionamento da sociedade em que estão inseridos e quais os meios possíveis para participação em sua gestão. As informações necessárias, porém, geralmente são elaboradas com inúmeros termos e jargões técnicos, o que dificulta sua compreensão. Buscando facilitar o acesso à essas informações, e aproveitando as vantagens da tecnologia aliadas às técnicas de linguagem simples (Fischer, 2018) seria possível considerar a utilização das redes sociais como ferramentas úteis na busca por aproximar o cidadão dos entes públicos que o representam.

Dessa forma, considerando a utilização das redes sociais como ferramentas no processo de Comunicação Pública, torna-se importante observar e compreender como os órgãos públicos já presentes nas redes sociais as utilizam e que tipo de informações são transmitidas através delas. Buscando responder à esta demanda, a presente pesquisa apresenta como objetivo identificar que tipos de informação no âmbito da Comunicação Pública foram disponibilizados pela Assembleia Legislativa de Mato Grosso através de seu perfil oficial no Instagram durante os anos de 2018 a 2020. Metodologicamente, a pesquisa é exploratória e com abordagem qualitativa.

Os resultados obtidos servirão como diagnóstico inicial e base para a criação de ferramentas inovadoras de apoio aos órgãos públicos, buscando otimizar a utilização dessas mídias, de forma a transmitir através delas informações rápidas, relevantes e em linguagem acessível, fomentando transparência e a participação social.

O presente artigo está dividido nas seguintes partes: a introdução, seguida dos principais conceitos que dão embasamento teórico a este estudo. Depois, são apresentadas as metodologias utilizadas e, na sequência, os dados coletados e analisados. Por fim, são apresentadas as considerações finais, bem como a indicação das referências consultadas.

\section{Fundamentação Teórica}

Esta seção trata dos principais conceitos envolvidos nesta pesquisa, em especial, a comunicação pública no campo das redes sociais. 
O processo de restauração da democracia no país despertou a necessidade de instrumentos que permitam à sociedade exercer seu papel de conhecer, participar e controlar as ações do Estado, buscando o bem comum e do interesse público (Vuolo et al., 2020). Brandão (2012) lembra que a própria noção de cidadania passou a ser vista de forma diferente nesses últimos tempos, assumindo uma forma menos passiva e mais participativa, onde o cidadão tem garantido o livre exercício de seus direitos e deveres, o que só é possível quando existem condições de informação e comunicação e, por esse motivo, a comunicação hoje pode ser considerada um ator político essencial na formação do novo espaço público. M. Duarte (2012) contribui com esse pensamento ao afirmar que a comunicação é uma importante ferramenta no processo de vivência da cidadania, seja viabilizando o acesso à informação ou estimulando debates ao disponibilizar canais que facilitem a participação do cidadão em algumas esferas deliberativas.

Brandão (2012) também aponta que, por muito tempo, o termo Comunicação Pública foi usado de forma genérica para identificar a comunicação feita pelos órgãos governamentais. Porém, há diferenças entre os conceitos de comunicação pública, governamental e política, termos próximos e interligados, porém com diferenças cruciais entre si. Para a autora, a comunicação governamental, de forma geral, é um termo utilizado para definir a comunicação feita pelo setor público, de mão única, normalmente com objetivo de construir a imagem de um órgão, dirigente ou político. A comunicação política é mais voltada para apresentar posicionamentos e opiniões, seja de um partido, candidato ou até mesmo órgão, geralmente com viés de convencimento. Já a ideia de comunicação pública envolve o foco na transmissão de informações ao cidadão, de forma que este possa exercer sua cidadania com maior efetividade e qualidade, o que é possível pois "coloca a centralidade do processo de comunicação no cidadão, não apenas por meio da garantia do direito à informação e à expressão, mas também do diálogo, do respeito a suas características e necessidades, do estímulo à participação ativa, racional e corresponsável” (J. Duarte, 2012, p. 61).

A Comunicação Pública, dessa forma, incentiva a participação do cidadão, estimulando o diálogo entre as partes, sendo possível levantar demandas, bem como apresentar dúvidas, opiniões e sugestões. Por sua vez, a tecnologia fornece ferramentas valiosas, pois com a utilização das TIC (Tecnologias de Informação e Comunicação), os cidadãos podem participar de debates expondo suas opiniões, bem como ser informados de assuntos de seus interesses no âmbito público ou até mesmo participar de votações acerca de assuntos de interesse público (Slaviero, Garcia e Maciel, 2012).

De forma geral, as práticas de Comunicação Pública são precedidas pela criação de uma cultura de transparência por parte das instituições públicas. No Brasil foram criados instrumentos legais que favorecem o desenvolvimento dessa cultura na gestão pública, tais como a Lei de Responsabilidade Fiscal (Brasil, 2000) e a Lei de Acesso à Informação (Brasil, 2011). Importante ressaltar que a transparência e a participação da sociedade são os pontos principais para que haja um efetivo controle social junto à administração pública (Vuolo et al., 2020) sendo a criação e cumprimento destas leis marcos importantes nesse processo.

Atendendo à legislação vigente, os órgãos públicos passaram a disponibilizar publicamente suas informações, entretanto, em relação a isso, M. Duarte (2012) alerta para o fato de que a informação disponibilizada nem sempre é a que o cidadão necessita. Geralmente as informações são apresentadas de forma complexas e cheias de termos 
técnicos, o que dificulta sua compreensão e impossibilita seu uso como ferramenta de controle social. Dessa forma, inspirada na técnica de redação Plain Language, já utilizada em diversos países, está se desenvolvendo no Brasil a linguagem simples. Também conhecida como linguagem cidadã (Carvalho e Cappelli, 2019), trata-se de um conjunto de práticas que tem por objetivo facilitar a leitura e a compreensão de textos de utilidade pública. Além disso, representa também uma causa social, já que defende o direito de todos a compreender informações relevantes em seu cotidiano (Fischer, 2018). Porém, fornecer informações e instruções de maneira clara, objetiva, em um linguajar de fácil compreensão requer uma mudança estrutural na comunicação pública como é realizada atualmente, e ainda há pouca aderência das organizações brasileiras em desenvolver planos de ação que visem tornar a comunicação com o cidadão mais simples (Fischer, Mont'Alvão e Rodrigues, 2019). O direito à informação é frequentemente citado em debates envolvendo o tema Comunicação Pública e, como lembrado por J. Duarte (2012), é um conceito particularmente relevante, já que trata de um meio para acesso a outros direitos do cidadão. A informação, quando assimilada, é a base primária do conhecimento, e seu estudo é tão relevante que o autor propõe um agrupamento da Informação no âmbito da Comunicação Pública em categorias, conforme descrito na Tabela 1.

Tabela 1. Categorias da Informação no âmbito da Comunicação Pública

\begin{tabular}{|c|l|}
\hline Institucionais & $\begin{array}{l}\text { Referentes ao papel, políticas, responsabilidades e funcionamento das organizações. } \\
\text { Em geral, são ligadas à projeção de imagem e à consolidação da identidade. }\end{array}$ \\
\hline De gestão & $\begin{array}{l}\text { Relativas ao processo decisório e de ação dos agentes que atuam em temas de inte- } \\
\text { resse público. Incluem discursos, relato de intenções, motivações, prioridades e ob- } \\
\text { jetivos dos agentes. }\end{array}$ \\
\hline $\begin{array}{c}\text { De utilidade } \\
\text { pública }\end{array}$ & $\begin{array}{l}\text { Sobre temas relacionados ao dia a dia das pessoas, geralmente serviços e orientações. } \\
\text { Buscam informar, mobilizar, prevenir ou alertar a população ou setores específicos } \\
\text { dela para temas de seu interesse. Informações legais, horários de eventos, campanhas } \\
\text { de vacinação, sinalização, causas sociais, sobre dados, direitos, produtos e serviços } \\
\text { à disposição do interessado e seu uso são exemplos típicos. }\end{array}$ \\
\hline $\begin{array}{c}\text { De interesse } \\
\text { privado }\end{array}$ & $\begin{array}{l}\text { As que dizem respeito exclusivamente ao cidadão, empresa ou instituição. Exemplos: } \\
\text { dados de Imposto de Renda, cadastros bancários. }\end{array}$ \\
\hline Mercadológicos & Referem-se a produtos e serviços que participam de concorrência de mercado. \\
\hline $\begin{array}{c}\text { De prestação de } \\
\text { contas }\end{array}$ & $\begin{array}{l}\text { Dizem respeito à explicação sobre decisões políticas e de uso de recursos públicos, } \\
\text { viabilizando o conhecimento, a avaliação e a fiscalização. }\end{array}$ \\
\hline $\begin{array}{c}\text { Dados públicos } \\
\text { Aqueles de controle do Estado que dizem respeito ao conjunto da sociedade e a seu } \\
\text { funcionamento. Exemplos: estatísticas, jurisprudência, documentos históricos, legis- } \\
\text { lação e normas. }\end{array}$ \\
\hline \multicolumn{2}{|c|}{ Fonte: Adaptado de J. Duarte (2012) }
\end{tabular}
Fonte: Adaptado de J. Duarte (2012).

As transformações em decorrência da revolução tecnológica estão diretamente relacionadas ao aumento na disseminação de informações. Nas últimas décadas, o acesso à informação se multiplicou com a criação de novas mídias e outros canais de comunicação. M. Duarte (2012) defende que esse panorama favorece o mecanismo de representação, por ser capaz de estimular a participação mais ativa dos cidadãos em decisões políticas, incentivando o diálogo entre representantes e representados.

Uma das maiores barreiras em comunicação, porém, não vem da falta de ferramentas na transmissão de informação, mas sim na dificuldade em fazer com que o cidadão (principal interessado) saiba que ela existe, onde está disponível e como pode utilizá-la para aumentar seu conhecimento ajudando a exercer de forma mais qualificada seu papel no controle social (J. Duarte, 2012). Fatores como a publicidade e a transparência são essenciais para a criação e manutenção de espaços (físicos e virtuais) que favoreçam a 
participação popular e o controle social, facilitando a comunicação entre o Estado e a população, possibilitando a obtenção de respostas para demandas sociais (Alves, 2018).

Lévy (2010, p. 13) afirma que "o aumento da transparência e a multiplicação dos contatos implicam uma nova velocidade de circulação das ideias e dos comportamentos", o que favorece a criação de iniciativas que busquem apresentar informações relevantes, de forma a munir o cidadão de conhecimento que possibilite seu exercício pleno de cidadania. Esse é o caso das redes sociais, espécies de comunidades virtuais, ou seja, "um grupo de pessoas que estão em relação por intermédio do ciberespaço" (Lemos, 2010, p. 101). Para o autor, as redes sociais caracterizam-se mais pela interação entre seus participantes do que pela própria tecnologia em si, que funciona em segundo plano, como um suporte. Devido ao alcance das redes sociais, se torna inegável seu potencial como ferramentas de Comunicação Pública, podendo estimular o controle social. Se bem utilizadas, elas podem contribuir para que se consolide a democracia em que estamos inseridos, fortalecendo o poder do cidadão ao fazê-lo compreender mais facilmente informações públicas e participar de forma mais efetiva nas decisões tomadas pelo poder público. Afinal, munido de mais informação o cidadão tem maior poder de controle.

Além disso, essas ferramentas surgem como uma opção às mídias de massa, principalmente representadas pela televisão, onde a informação é controlada de acordo com interesses específicos. Lemos (2010) defende que as mídias livres são condição básica para o exercício da democracia. A estrutura das mídias na Internet é mais aberta, colaborativa e flexível, o que pode ser um ponto positivo no diálogo entre os atores envolvidos nesse processo comunicativo. Para a utilização destes novos meios comunicacionais é importante capacitar as organizações, não apenas em relação às tecnologias utilizadas, mas principalmente sobre a própria comunicação em si. J. Duarte (2012) reforça que é essencial que os agentes públicos compreendam sua importância, reconheçam suas possibilidades e usos, e busquem constantemente qualificar os meios de contato entre instituições e seus diferentes públicos.

\section{Metodologia}

A presente pesquisa tem como objetivo geral identificar que tipos de informação no âmbito da Comunicação Pública foram disponibilizados pela Assembleia Legislativa de Mato Grosso em seu perfil oficial no Instagram durante os anos de 2018 a 2020. O estudo, de cunho exploratório, se propôs a executar as seguintes ações: realizar pesquisa bibliográfica para embasamento teórico da pesquisa; coletar dados referentes às publicações da Assembleia Legislativa de Mato Grosso em seu perfil oficial na rede social Instagram no período entre janeiro de 2018 e dezembro de 2020; e identificar os tipos predominantes de informação transmitidos através das postagens do perfil durante o período estudado e de acordo com parâmetros sugeridos na literatura sobre Comunicação Pública.

A coleta foi realizada manualmente através de acesso à rede social e abrange publicações feitas no período entre $1^{\circ}$ de janeiro de 2018 e 31 de dezembro de 2020 , do perfil@assembleiamt. Na amostra foram consideradas somente as postagens orgânicas, já que estas passam a integrar o perfil @assembleiamt e podem ser visualizadas de forma histórica. Nesta pesquisa não foram consideradas as postagens patrocinadas (pagas), que permanecem ativas apenas pelo tempo pré-definido (contratado) pelo gestor do perfil, não sendo possível consultá-las posteriormente. Pelo mesmo motivo, também não foram 
incluídos os stories, postagens disponíveis para visualização somente pelo período de vinte e quatro horas (Instagram, 2021).

Para esta pesquisa também não foram apresentados os dados referentes ao engajamento (quantidade de curtidas, visualizações de vídeos e comentários), pois o Instagram retirou a possibilidade de visualização automatizada destes dados por outros usuários que não sejam o próprio gestor ou dono do perfil. $\mathrm{O}$ estudo destes dados é importante para traçar estratégias de comunicação, porém após a mudança na plataforma, somente o próprio órgão público poderia realizá-lo.

As imagens, vídeos curtos e textos que compõem as publicações foram reunidas para posterior classificação de acordo com o tipo de informação transmitida e utilizando como parâmetro as categorias de informação no âmbito da Comunicação Pública sugeridas por J. Duarte (2012) e detalhadas na etapa teórica desta pesquisa. Por suas características as publicações foram classificadas entre as categorias: institucional, de gestão, de utilidade pública, de interesse privado, mercadológico, prestação de contas e dados públicos.

O método utilizado para a organização e análise dos dados foi a análise de conteúdo que, segundo Franco (2018) tem como ponto de partida a mensagem. Através de categorização das publicações (mensagens) foi possível identificar quais tipos de informação apareceram com maior frequência nas postagens do perfil oficial do órgão no Instagram durante os anos de 2018 a 2020, com vistas a resposta ao problema de pesquisa.

\subsection{Assembleia Legislativa de Mato Grosso}

A Assembleia Legislativa de Mato Grosso é o órgão do Poder Legislativo no estado de Mato Grosso e conta com 24 Deputados Estaduais escolhidos democraticamente através de voto. Localiza-se em Cuiabá, capital do estado de Mato Grosso. É possível observar na Identidade Organizacional do órgão o compromisso assumido em relação ao "fortalecimento da democracia e desenvolvimento do Estado com a participação da população". Possui como Visão "Ser reconhecida como instituição de referência na representatividade da sociedade" (ALMT, 2019) e entre seus Valores estão, além da representatividade, a qualidade, transparência, credibilidade e compromisso. $\mathrm{O}$ fato de apresentar estas características em sua identidade organizacional contribuiu para que fosse a selecionada para o estudo. O órgão possui alguns canais oficiais de comunicação, como a TVAL - TV Assembleia MT e a Rádio Assembleia. Também está presente nas redes sociais Facebook com o perfil \facealmt, e no Instagram identificado como @assembleiamt, o perfil estudado nesta pesquisa.

\subsection{Instagram}

O Instagram é uma rede social com foco no compartilhamento de imagens. Foi criado no ano de 2010, comprado pelo grupo Facebook em 2012 e conta com mais de 1 bilhão de usuários ativos no mundo (Instagram, 2021). De acordo com a pesquisa Social Media Trends (Rock Content, 2019), o Instagram figura entre as redes sociais mais utilizadas pelos brasileiros. Por se tratar de uma plataforma ágil, onde as imagens são visualizadas de forma rápida e contínua, seu uso é feito com maior frequência via telefones celulares e outros dispositivos móveis. Os principais tipos de postagens disponíveis no Instagram são: as postagens orgânicas, publicações gratuitas que se tornam parte integrante do histórico do perfil, ficando disponíveis para consulta posterior (podem ser imagens ou 
vídeos de no máximo um minuto); as postagens patrocinadas, que têm fins mercadológicos, são feitas com direcionamento à públicos específicos e exibidas por um período pré-definido (após o tempo contratado são retiradas do perfil, impossibilitando consultas posteriores); e os stories, publicações disponíveis apenas pelo período de vinte e quatro horas (também não podem ser consultadas posteriormente). Recentemente, a rede social também disponibilizou aos usuários os recursos Reels, que permite gravação ou inclusão de vídeos de até quinze segundos, e o IGTV, dedicado a vídeos mais longos (Instagram, 2021).

A escolha desta rede social se deu principalmente pelo seu crescimento de uso entre brasileiros, pela dinâmica da plataforma, que apresenta postagens mais padronizadas (imagens e vídeos curtos) e permite sua visualização histórica, viabilizando a coleta de dados para esta pesquisa. Por definição metodológica foram consideradas somente as postagens orgânicas do perfil @assembleiamt.

\section{Resultados e Discussões}

No período entre os anos de 2018 e 2020 foram feitas ao todo 362 postagens orgânicas no perfil oficial do Instagram @assembleiamt. Em relação à quantidade total de postagens observou-se uma oscilação entre os anos (Tabela 2). Durante o ano de 2018 foi feito um pequeno número de postagens com intervalos irregulares entre elas (apenas 49 publicações com intervalos que chegavam até a mais de 20 dias). A partir de 2019 foi possível observar um aumento na quantidade e maior regularidade entre as postagens (186 ao todo, um aumento de $279,59 \%$ em relação ao ano anterior). Já o ano de 2020 apresentou uma quantidade total de 127 postagens, ou seja, 31,72\% menor que 2019, ainda assim apresentando crescimento de 159,18\% se comparada com 2018.

Tabela 2. Classificação das postagens do perfil @assembleiamt - 2018 a 2020

\begin{tabular}{|l|c|c|c|}
\hline \multicolumn{1}{|c|}{ Categoria } & $\begin{array}{c}\text { Quantidade de } \\
\text { postagens 2018 }\end{array}$ & $\begin{array}{c}\text { Quantidade de } \\
\text { postagens 2019 }\end{array}$ & $\begin{array}{c}\text { Quantidade de } \\
\text { postagens 2020 }\end{array}$ \\
\hline Gestão & 20 & 7 & 4 \\
\hline Institucional & 13 & 11 & 2 \\
\hline Prestação de contas & 9 & 129 & 53 \\
\hline Utilidade Pública & 7 & 39 & 68 \\
\hline Interesse Privado & 0 & 0 & 0 \\
\hline Mercadológico & 0 & 0 & 0 \\
\hline Dados Públicos & 0 & 0 & 0 \\
\hline TOTAL & $\mathbf{4 9}$ & $\mathbf{1 8 6}$ & $\mathbf{1 2 7}$ \\
\hline
\end{tabular}

Fonte: Dados coletados do perfil @assembleiamt no Instagram referentes ao periodo 01/01/2018 a $31 / 12 / 2020$.

As postagens integrantes da amostra estudada foram classificadas de acordo com as informações transmitidas, utilizando como parâmetro as categorias de informação no âmbito da Comunicação Pública. Como resultado (Figura 1), observou-se uma oscilação em relação às categorias predominantes durante o período analisado. Em 2018, as categorias mais frequentes foram a de "Gestão" (com 41\% das postagens), seguida da categoria "Institucional" com $27 \%$. A categoria "Prestação de contas" aparece com 18\% e "Utilidade Pública" com 14\% das publicações. Durante o ano de 2019, já foi possível observar uma mudança na predominância das categorias, sendo que as mais observadas no período foram "Prestação de contas" (com 69\% das postagens) e "Utilidade Pública" com $21 \%$ do total, enquanto "Gestão" (4\%) e "Institucional" (6\%) aparecem com uma 
presença reduzida em relação ao ano anterior. Já no ano de 2020, as categorias mais observadas continuam sendo as mesmas do ano anterior: "Utilidade Pública" (53\%) e "Prestação de contas" (42\%). Neste ano as categorias "Gestão" (3\%) e "Institucional" $(2 \%)$ continuam representando bem pouco da quantidade total das postagens. No período estudado não foram observadas postagens que se enquadrassem nas categorias Interesse Privado, Mercadológico e Dados Públicos.

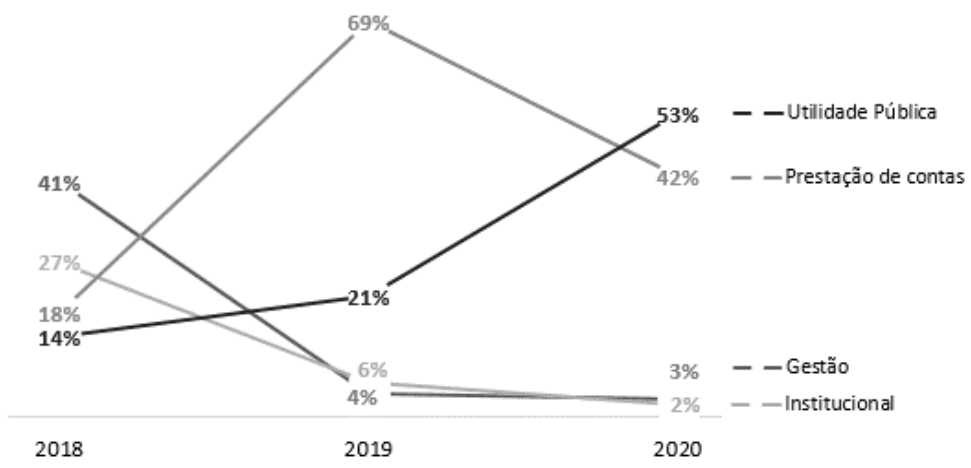

Figura 1. Classificação das postagens do perfil @assembleiamt - 2018 a 2020

A categoria de Gestão traz postagens relacionadas às ações dos órgãos e agentes atuando em temas de interesse público, incluindo "discursos, relatos de intenção, motivações, prioridades e objetivos dos agentes" (J. Duarte, 2012, p. 62). Esta categoria representou $41 \%$ do total de postagens de 2018, porém em 2019 e 2020 representou apenas $4 \%$ e $3 \%$ do total respectivamente. As publicações observadas nesta categoria foram vídeos curtos com intenções e projetos apresentados por Deputados Estaduais eleitos e servidores do órgão.

Já a categoria Institucional traz publicações relacionadas ao papel, responsabilidades e funcionamento das organizações. Em 2018 esta categoria correspondeu a $27 \%$ do total das publicações, porém em 2019 sua participação diminuiu apenas para $6 \%$ e em 2020 para apenas $2 \%$ das postagens observadas. Entre os exemplos algumas das postagens trazem atribuições e responsabilidades de órgãos e agentes públicos apresentados de forma rápida, com conceitos e imagens simples (como exemplo: as funções de um Deputado Estadual). Também foram identificadas publicações que visam o fortalecimento de imagem da própria instituição, apresentando registros de atividades desenvolvidas na Assembleia Legislativa (pós-graduação na Instituição, eventos realizados e fotos de Sessões, por exemplo).

Prestação de Contas é uma categoria que envolve "explicação sobre decisões políticas e de uso de recursos público, viabilizando o conhecimento, a avaliação e a fiscalização" (J. Duarte, 2012, p. 62). Esta categoria teve uma representação menor no ano de 2018 (apenas 18\% do total das postagens), porém nos anos de 2019 e 2020 foi possível observar um aumento considerável na presença de publicações com estas características (representando $69 \%$ e $42 \%$ do total respectivamente). Entre as publicações desta categoria estão incluídas as que apresentam divulgação de Projetos de Lei em discussão pelo legislativo, bem como informações sobre Audiências Públicas que acontecem no órgão e são abertas para a participação da sociedade. Também foram observadas prestações de contas sobre decisões e ações parlamentares executadas em relação a um período ou tema específico, como por exemplo: Balanço Anual de atividades 
do ano e Informativo sobre ações da ALMT relativas ao período de pandemia da doença COVID-19. É comum nestas postagens serem acrescentados links de direcionamento para o site da Assembleia Legislativa onde é possível acessar ao conteúdo completo sobre os temas e, caso desejado, opinar através dos meios disponíveis.

As postagens da categoria Utilidade Pública são comumente relacionadas ao cotidiano dos cidadãos e envolvem geralmente orientações, divulgações de eventos, campanhas de conscientização, lembranças de datas comemorativas, bem como informativos de direitos garantidos por lei e serviços disponíveis à população. No ano de 2018 a categoria Utilidade Pública representou apenas 14\% do total das publicações, mas nos anos seguintes foi possível observar sua maior presença e importância no perfil da ALMT, passando a representar 21\% das publicações em 2019 e 53\% do total no ano de 2020. Entre as publicações nesta categoria as mais observadas foram: as lembranças de datas comemorativas (que no caso do perfil da ALMT geralmente vêm acompanhadas de contextualização e informações sobre legislação pertinente ao tema), diversas campanhas de conscientização (campanha de doação da medula óssea, campanha contra fake news, entre outras), informações sobre direitos do cidadão garantidos por legislação estadual, divulgação das datas de cursos e outros eventos abertos à sociedade, e também divulgação de programação disponibilizada pela TV e pela Rádio Assembleia. Como exemplo de postagem da categoria Utilidade Pública cita-se a divulgação de aulas preparatória para o Exame Nacional do Ensino Médio (ENEM) oferecidas gratuitamente através de alguns canais de comunicação da Assembleia Legislativa (site, TV Assembleia, e Facebook).

Durante o período entre os anos de 2018 e 2020, foi possível observar uma mudança em relação às categorias de informação divulgadas de forma predominante no perfil. No ano de 2018 a predominância foi da categoria "Gestão" (41\% das postagens), o que demonstrava uma tendência do órgão em utilizar a rede social para transmitir à população as intenções e motivações dos agentes que atuam como representantes dos cidadãos. O fato de a categoria "Institucional" aparecer em seguida (com 27\%) demonstrava intenção em esclarecer as atribuições das instituições e agentes públicos, bem como fortalecer a imagem da própria Assembleia Legislativa perante a sociedade ao exibir registros de atividades realizadas pelo órgão. As categorias "Prestação de Contas" e "Utilidade Pública" aparecem neste ano com apenas 18\% e 14\% respectivamente.

Ao analisar os dados dos anos seguintes (2019 e 2020) foi possível observar uma alteração na predominância de categorias. Neste período, a participação de postagens nas categorias "Prestação de Contas" e "Utilidade Pública" tornou-se muito maior (em 2020 representaram respectivamente $42 \%$ e $53 \%$ do total), o que indica a tendência do órgão em divulgar informações sobre decisões políticas que envolvam e que sejam de interesse da sociedade, bem como divulgar serviços disponíveis, legislações, campanhas e outras informações que sejam de utilidade pública. Neste mesmo período (2020), a categoria "Gestão" correspondeu a 3\% das postagens totais e "Institucional" apenas 2\% do total.

Sabe-se que o foco principal do Instagram são as imagens e informações rápidas e, por possuir essa característica, não é uma rede social muito utilizada como catalizadora de discussões mais elaboradas entre seus usuários, porém é uma ferramenta valiosa na transmissão de informações simples e ágeis, que podem agregar conhecimento e fortalecer diálogos futuros entre o setor público e o cidadão através de outros meios. Nesse sentido, foi possível observar que a Assembleia Legislativa de Mato Grosso utilizou a rede social se aproveitando desta característica principal, ou seja, focou na 
disseminação de informações rápidas, como convites para Audiências Públicas, apresentações breves de Projetos de Lei, divulgação de campanhas, entre outros.

\section{Considerações Finais}

Pesquisas recentes indicam aumento na utilização das redes sociais pelos brasileiros, dados que reforçam seu potencial de alcance como ferramentas na transmissão de informação rápida e em grande escala. Seguindo essa tendência, a administração pública tem buscado se atualizar em relação às transformações tecnológicas, no intuito de utilizálas a favor do processo comunicacional entre o poder público e a sociedade, disponibilizando informações que possibilitem ao cidadão exercer com maior qualidade seu papel no controle social.

Dessa forma, considerando a utilização das redes sociais como ferramentas de Comunicação Pública, esta pesquisa se propôs a observar como a Assembleia Legislativa de Mato Grosso utilizou seu perfil oficial no Instagram nos anos de 2018 a 2020. Após a análise dos dados coletados, observou-se que o uso deste perfil no Instagram apresentou mudanças em relação aos tipos de informação transmitidos no período estudado.

Durante o ano de 2018 havia a predominância das categorias "Gestão", o que demonstrava que o uso principal da rede social era voltado a transmitir as intenções e motivações dos agentes que representam a sociedade junto ao órgão, e "Institucional" que tem por objetivo fortalecer a imagem da organização perante a sociedade. A partir de 2019, porém, o perfil de utilização da rede social apresentou mudanças, entre elas a predominância do tipo de informação transmitida através das postagens. A partir desse período as categorias mais observadas foram "Prestação de Contas", o que demonstra interesse do órgão em aproveitar a rede social para divulgar informações sobre suas decisões políticas, de forma a possibilitar conhecimento e fiscalização por parte da sociedade, e "Utilidade Pública", que tem como principal característica a divulgação de serviços disponíveis ao cidadão, de legislações ligadas ao cotidiano, campanhas e outras informações que sejam de interesse público. Com a análise dos resultados, foi possível observar que a instituição utiliza seu perfil na rede social para a transmissão de informações de utilidade pública e interesse do cidadão, apresentadas de forma simples e direta, o que demonstra uma atitude positiva em relação ao aproveitamento das características da ferramenta.

O período de isolamento social causado pela pandemia da doença COVID-19 evidenciou a importância da utilização responsável destas tecnologias, já que neste período, a diminuição do contato e dos atendimentos presenciais fez com que grande parte das informações chegasse ao cidadão através da internet. Além disso, cabe salientar que há casos de utilização leviana das redes sociais no intuito de disseminar informações falsas ou tendenciosas - as fake news - o que causa transtornos, prejuízos ou consequências mais sérias aos envolvidos. Por motivos como esses, torna-se imperativo estudar e buscar formas de utilização das redes sociais que beneficiem seus usuários e a sociedade como um todo, e que tragam ao cidadão notícias, prestações de contas e informações verdadeiras, com credibilidade e linguagem acessível.

Uma limitação percebida durante a pesquisa foi a ausência dos dados de engajamento (curtidas, compartilhamentos, comentários, entre outros). Esses dados são importantes na elaboração de estratégias de utilização das redes sociais, porém são visualizados somente pelo próprio gestor do perfil. 
Pesquisas como esta são parte de um diagnóstico que possibilita reunir informações que servirão como base para estudos futuros. Mostra-se necessária a criação de métodos inovadores que auxiliem as equipes de comunicação dos órgãos públicos na gestão de suas redes sociais, otimizando suas funcionalidades, sem deixar de atender a todos os requisitos legais e sociais específicos do setor público. Também poderão ser realizados novos estudos com foco na utilização da linguagem simples nas redes sociais, fornecendo material de apoio para criação de conteúdo relevante, porém apresentado de forma clara e objetiva, sendo facilmente compreendido pelo cidadão comum. É importante lembrar que, neste momento, a pesquisa foi desenvolvida somente com o Instagram pelas características da plataforma, porém estudos futuros também poderão incluir em seu escopo outras redes sociais relevantes, bem como análises dos dados de engajamento (a serem obtidos juntos aos gestores das contas). Novas pesquisas nesta área são importantes, pois podem auxiliar os órgãos públicos a aproveitar o potencial dessas ferramentas na disseminação de conhecimento, fomentando transparência e participação social.

\section{Agradecimentos}

Essa pesquisa teve apoio do Conselho Nacional de Desenvolvimento Científico e Tecnológico (CNPq) - Bolsa Produtividade em Pesquisa.

\section{Referências}

ALMT. (2019) "Plano Estratégico Longo Prazo 2019-2024". Disponível em: http://www.al.mt.gov.br/arquivos/institucional/planejamento-estrategico/planoestrategico-2019-2024.pdf Acesso em: 17 de janeiro de 2021.

Alves, E. O. (2018) "Transparência e publicidade nos Conselhos Gestores de Políticas Públicas pelas Redes Sociais". In: Vuolo, C. L., Maciel, C. and dos Anjos, A. M. (Org.). Educação à distância: [in]formação em cidadania e controle social. Cuiabá: EdUFMT. E-pub.

Brandão, E. P. (2012) “Conceito de comunicação pública”. In: DUARTE, J. (Org.) Comunicação Pública: Estado, Mercado, Sociedade e Interesse Público. 3. ed. São Paulo: Atlas.

Brasil. (2000). "Lei Complementar No 101/2000, de 04 de maio de 2000". Estabelece normas de finanças públicas voltadas para a responsabilidade na gestão fiscal e dá outras providências. Brasília: DF. Disponível em: http://www.planalto.gov.br/ccivil_03/leis/lcp/lcp101.htm.

Brasil. (2011). "Lei $N^{\circ} 12.527 / 2011$, de 18 de novembro de 2011". Regula o acesso a informações previsto no inciso XXXIII do art. $5^{\circ}$, no inciso II do $\S 3^{\circ}$ do art. 37 e no $\S$ $2^{\circ}$ do art. 216 da Constituição Federal; [...]. Brasília: DF. Disponível em: http://www.planalto.gov.br/ccivil_03/_ato2011-2014/2011/lei/112527.htm.

Carvalho, L.P. and Cappelli, C. (2019) "Linguagem Cidadã de Processos em Sistemas Digitais". In: Anais do $17^{\circ}$ Congresso Internacional de Ergonomia e Usabilidade de Interfaces Humano-Tecnologia e o $17^{\circ}$ Congresso Internacional de Ergonomia e Usabilidade de Interfaces e Interação Humano-Computador, p. 1-13. São Paulo: Blucher.

Duarte, J. (2012) "Instrumentos de comunicação pública”. In: Duarte, J. (Org.) 
Comunicação Pública: Estado, Mercado, Sociedade e Interesse Público. 3. ed. São Paulo: Atlas.

Duarte, M. Y. M. (2012) “Comunicação e cidadania”. In: Duarte, J. (Org.) Comunicação Pública: Estado, Mercado, Sociedade e Interesse Público. 3.ed. São Paulo: Atlas.

Fischer, H. (2018) "Clareza em textos de e-gov, uma questão de cidadania". Rio de Janeiro: Com Clareza. E-book.

Fischer, H., Mont'Alvão, C. and Rodrigues, E. (2019) "Fator facilitador ou barreira para cidadãos acessarem e-serviços: o papel do texto em governo eletrônico". In: Anais do $17^{\circ}$ Congresso Internacional de Ergonomia e Usabilidade de Interfaces HumanoTecnologia e o $17^{\circ}$ Congresso Internacional de Ergonomia e Usabilidade de Interfaces e Interação Humano-Computador, p. 250-265. São Paulo: Blucher.

Franco, M. L. P. B. (2018) “Análise de Conteúdo”. 5. ed. Campinas: Editora Autores Associados.

Instituto Brasileiro de Geografia e Estatística. (2020) "Pesquisa Nacional por Amostra de Domicílios Contínua - Acesso à Internet e à televisão e posse de telefone móvel celular para uso pessoal 2018". Rio de Janeiro: IBGE. Disponível em: https://biblioteca.ibge.gov.br/visualizacao/livros/liv101705_informativo.pdf

Instagram. (2021) “About us”. Disponível em: https://about.instagram.com/ Acesso em 02 de abril de 2021.

Lemos, A. and Lévy, P. (2010) "O futuro da internet: em direção a uma ciberdemocracia". São Paulo: Paulus.

Lévy, P. (2010) “Cibercultura”. 3. ed. São Paulo: Editora 34.

Rock Content. (2019) "Social Media Trends 2019: panorama das empresas e dos usuários nas redes sociais". Disponível em: https://materiais.rockcontent.com/social-mediatrends Acesso em: 21 de janeiro de 2021.

Santos, J. and Harmata, F. (2013, julho) "Análise de Caso da Prefeitura de Curitiba - A relação entre humor e serviço público na comunicação em redes sociais". In Anais do XVIII Congresso de Ciências da Comunicação na região Sudeste. Bauru: Intercom.

Slaviero, C., Garcia, A. C. B. and Maciel, C. (2012) "Métodos de participação e Tecnologias de Informação e Comunicação: transformando participação em eParticipação". In: Anais do IV Workshop de Computação Aplicada em Governo Eletrônico, p. 17-24. Porto Alegre: Sociedade Brasileira de Computação.

TV Senado. (2018, maio 24) "Legislativo e Mídias Sociais - Seminário 24/05/2018". [Arquivo de vídeo]. Disponível em: https://www.youtube.com/watch?v=eGScrdi5hhU

Vuolo, C. L. C., Maciel, C., Auerswald, A. A. G. B., dos Anjos, R. A., dos Anjos, A. M., de Oliveira, C., and Mansilla, D. P. (2020) "Formando Cidadãos para a Cidadania e Controle Social: Levantamentos de uma Experiência". In Anais do VIII Workshop de Computação Aplicada em Governo Eletrônico, p. 12-23. Porto Alegre: Sociedade Brasileira de Computação. doi: 10.5753/wcge.2020.11254 